\title{
ASPECTOS CONCEITUAIS E METODOLÓGICOS DE INTERPRETAÇÃO PALEOAMBIENTAL DA SÉRIE SERRA DO ESPIGÃO, BACIA DO PARANÁ
}

\author{
ERCÍLIO GAMA JR.*
}

\begin{abstract}
This paper deals with the palaeoenvironmental interpretation of the Serra do Espigano Series (Later Permian) of the Paraná Basin in Southern Brazil. Following the Modern Stratigraphy approach, the results of Sequential Analysis, Facies Analysis, and Depositional Systems Mapping are integrated. The Sequential Analysis made possible the identification of this stratigraphic unit as a depositional episode of third order, which is pointed out by the lateral filling of a pre-existing gulf by coastal progradation. The Facies Analysis and Depositional Systems Mapping, carried out on the depositional sequence of this episodic event, reassert the former palaeographic reconstruction built up by three depositional systems: Serra Alta epineritic shelf, Corumbatá tidal flat, and Serra do Espigão delta system. Based on this time-space diagnosis the whole Permian-Carboniferous sequence of the Parana Basin is interpreted as a facies-cycle wedge, where the Irati carbonates identify the standstill and reversion from transgressive to the regressive phase.
\end{abstract}

\begin{abstract}
INTRODUÇÃO
O Grupo Passa Dois da Bacia do Paraná foi objeto, recentemente, de um ensaio de revisão crítica (Mendes 1984) no qual são sintetizadas e analisadas as diversas interpretações paleoambientais que, nestes últimos anos, têm sido propostas por diversos pesquisadores da comunidade geológica brasileira. Depreende-se desta análise uma diversidade muito grande de interpretaçoes que variam de ambientes lacustres a mares epicontinentais, incluindo ambientes litorâneos como deltas, planícies de maré e lagunas. Essas controvérsias são atribuídas pelo referido autor à insuficiência ou complexidade dos dados físicos e biológicos necessários a uma determinação precisa dos ambientes deposicionais.

O propósito deste trabalho é demonstrar que as divergências interpretativas sobre o Grupo Passa Dois decorrem, em parte, da utilização de métodos inadequados aos novos conhecimentos trazidos pelo que se convencionou chamar de Moderna Estratigrafia do que da suposta complexidade de seus sedimentos. Preliminarmente, são apresentadas as linhas básicas de uma sistemática de interpretação paleogeográfica, em que esses novos conhecimentos são discutidos, integrando-os, ao mesmo tempo, aos conceitos e métodos multidisciplinares clássicos.
\end{abstract}

\section{A MODERNA ESTRATIGRAFIA A Estratigrafia} atravessa nestes últimos 20 anos uma fase de extraordinário avanço conceitual e metodológico. Introduzindo novos conceitos e metodologias, a moderna interpretação estratigráfica evoluiu para a atual Análise de Bacia, liberando-se dos esquemas clássicos da "estratigrafia de formações tabulares" (layer cake stratigraphy), na qual a ênfase era dirigida ao reconhecimento, correlação e interpretação de unidades tabulares, supostamente homogêneas e isócronas. Miall (1985) aponta cinco pontos principais desta evolução, quẻ designou como the modern revolution in stratigraphy. São eles:

- $\mathrm{O}$ desenvolvimento da Análise da Fácies em Sedimentologia - que permitiu uma precisa compreensão de que as fácies são resultantes de processos sedimentares, desmitificando conseqüentemente, a clássica relação fácies/ambiente.

- A introdução do conceito de sistemas deposicionais (Fischer \& McGowen 1967) - que, baseado no trinômio fácies-processo sedimentar-ambiente e na Lei de Correlação de Fácies de Walther, possibilitou o reconhecimento e o mapeamento de unidades genéticas equivalentes às modernas privíncias fisiográficas ou geomorfologicas.
- A introdução da estratigrafia sísmica - que permitiu rastrear espacialmente as seqüências deposicionais (Vail et al. 1977), propiciando uma melhor compreensão da natureza cíclica ou episódica da sedimentação e de suas relações estratigráficas.

- O desenvolvimento da Tectônica de Placas - que propiciou uma reavaliação dos conceitos sobre a evolução de bacias e seus estilos sedimentares.

- Finalmente, o refinamento da cronoestratigrafia pela introdução de técnicas radiométricas e, mais recentemente, da magnetoestratigrafia.

Esses avanços conceituais e metodológicos provocaram uma profuinda reformulação na concepção científica pertinente, de tal sorte que "a disciplina estratigráfica tornou-se uma ciência completamente nova, guardando pouca semelhança com a temática descrita nos livros-textos clássicos como Dumbar \& Rodger (1957) ou Krumbein \& Sloss (1963)", (Miall 1985, p. 3).

Como decorrência, a interpretação paleoambiental evoluiu dos modelos abstratos da análise sedimentológica para verdadeiras reconstituiçóes paleogeográficas, pelo mapeamento de unidades genéticas, desenvolvidas durante os episódios de sedimentação.

A moderna concepção deposicional fundamenta-se no fato de a sedimentação se processar em ciclos ou episódios naturais, de três ou quatro ordens de grandeza, controlados por variações eustáticas do nível do mar. Em cada episódio, a bacia é dominada por uma paisagem geográfica específica. Assim, a seqüência deposicional que materializa este evento deposicional constitui uma unidade-tempo de caráter natural na interpretação paleogeogrảfica.

No decurso do episódio, a sedimentação resulta đa ação de processos físicos, químicos e/ou biológicos atuantes nos diversos ambientes constituintes das províncias de sedimentação desta paisagem geográfica. $\mathrm{A}$ associação de fácies de cada província de sedimentação materializa o sistema deposicional que representa, assim, uma unidade-espaço natural de interpretação.

A interação das taxas de sedimentação e subsidência determina o empilhamento das fácies sedimentares, cujo arranjo tridimensional $\hat{\epsilon}$, por sua vez, controlado pelo sentido da variação de nível do mar no decurso do episódio. Nessas condições, o empilhamento será progradacional ou retrogradacional em consonância com a variação negativa ou positiva do nível 
do mar. Em ambos os casos, a sucessão vertical das fácies sedimentares na seqüência deposicional refletirá a distribuição horizontal dos ambientes nas provincias de sedimentação e destas na paisagem geográfica reinante durante o episodio. Em síntese, a cada episódio corresponde uma configuração ambiental e, conseqüentemente, cada seqüência deposicional representa um trato de sistemas deposicionais.

Sob a luz desta concepção, a moderna interpretação paleogeográfica cristaliza-se num diagnóstico de espaço e de tempo. No espaço, pela identificação das províncias fisiográficas ou geomorfológicas de sedimentação, que além do ambiente subaquoso terminal inclui, necessariamente, os ambientes responsáveis pelo suprimento e pela dispersão de terrígenos. E no tempo, pela identificação do episódio de sedimentação, sua origem, duração e natureza transgressiva ou regressiva, refletida no padrāo de empilhamento de sua seqüência deposicional. A interpretação final deve traduzir, portanto, a sedimentação e a evolução de sua paisagem geográfica no decurso de um ciclo ou episódio deposicional.

Os aspectos multidisciplinares envolvidos nessa concepção tornam a interpretação paleoambiental uma pesquisa que transcende a simples Análises de Fácies. Sua abrangência incorpora a Análise Sequiencial e Mapeamento de Sistemas Deposicionais e exige em decorrência, a adoção de uma sistemática que racionalize a integração dos dados estratigráficos, sedimentologicos, paleontológicos e geoquímicos pertinentes. Essa sistemática inclui estudos específicos efetivados em três diferentes níveis ou etapas, que se complementam sucessivamente. A figura 1 ilustra um quadro que relaciona essas etapas com as disciplinas afins e objetivos pretendidos.

\begin{tabular}{|c|c|c|c|}
\hline & ETAPAS & DISCIPLINAS AFINS & OBJETIVOS \\
\hline$\{9$ & $\begin{array}{l}\text { Andilise } \\
\text { Sequêncial }\end{array}$ & $\begin{array}{l}\text { Sismoestrotigrofto, } \\
\text { Bioestratigrafio a } \\
\text { Anólise de Perfis }\end{array}$ & $\begin{array}{l}\text { Reconhecimento dos } \\
\text { eplsódios (sedimentos } \\
\text { termpordimente associodos) }\end{array}$ \\
\hline 29 & $\begin{array}{l}\text { And́lise } \\
\text { fócies }\end{array}$ & Sedimentologio & $\begin{array}{l}\text { Interpretoçöo dos } \\
\text { Processos Sedimentores }\end{array}$ \\
\hline 38 & $\begin{array}{l}\text { Mopeomento de } \\
\text { Sisternos Deposicionoin }\end{array}$ & $\begin{array}{l}\text { Estratigrafia, Integroçäo } \\
\text { Sedimentologio-Paleontologia }\end{array}$ & $\begin{array}{l}\text { Reconstituiçojo } \\
\text { Paleogeogrófica }\end{array}$ \\
\hline
\end{tabular}

Figura I-Sistemática de interpretação paleogeografica

A primeira etapa refere-se à identificação da seqüência deposicional que materializa o episódio de sedimentação. Seu objetivo imediato $\varepsilon$ o reconhecimento dos sedimentos temporalmente associados, valendo-se para tanto da sismoestratigrafia, bioestratigrafia ou analise de perfis geofísicos.

A etapa subseqüente constituiu a análise das fácies contidas na sequiência deposicional identificada. Em escala de afloramentos ou de amostras laboratoriais, este estudo sedimentológico visa a interpretaçăo dos processos sedimentares e, por extensão, da hidrodinâmica do meio ambiente.

A interpretação paleoambiental se completa como reconstrução paleogeográfica com o mapeamento dos sistemas deposicionais. Esses mapas reconstituem, geograficamente, as províncias geomorfológicas ou fisiograficas inferidas. Os sistemas deposicionais são unidades tridimensionais constituídas por uma associação de fácies desenvolvida em cada província de sedimentação. No reconhecimento dos sistemas deposicionais, as evidências paleontológicas e geoquímicas são igualmente relevantes.
É evidente que a aplicação dos conceitos de sequêencia deposicional e sistema deposicional como unidades naturais de interpretação genética implica, necessariamente, o abandono ou desconsideração da divisão litoestratigráfica formal. As formaçōes, estes "frankensteins estratigráficos", são, por definição, unidades artificiais delimitadas por critérios operacionais de mapeamento, sem nenhuma conotação genética ou temporal. A subordinação dos estudos paleoambientais a essas unidades artificiais é a principal razão das interpretações controvertidas.

ANÁLISE SEQÜENCIAL As idéias básicas que suportam a concepção de sedimentação episódica (back to the layer cake) são conhecidas da Estratigrafia desde a década de 30. Os ciclotemas de Wanless \& Weller (1932) sobre os depó. sitos carboníferos da América do Norte e Europa, as sequêencias sedimentares de Sloss (1963), os episódios glaciais precambrianos e paleozóicos de extensấo hemisférica e o próprio estabelecimento de algumas unidades geocronológicas da $\mathrm{Eu}$ ropa Ocidental trazem implícita a noção de episódios construtivos de sedimentação separados por hiatos ou descontinuidades. Estas, por sua vez, são reconhecidas por unidades destrutivas, unidades de sedimentação passiva ou mesmo discordâncias. Entretanto, foi com a Sismoestratigrafia que se obteve uma compreensão definitiva desta questão. Vail et al. (1977) propuseram o conceito de seqüência deposicional para uma sucessão relativamente concordante de estratos geneticamente associados. Limitada no topo e na base por discordâncias ou descontinuidades deposicionais, a seqüência deposicional possui uma conotação cronoestratigráfica estabelecida por critérios físicos. Em outras palavras, a seqüência deposicional representa um ciclo natural de sedimentação de uma paisagem geográfica implantada por uma variação relativa do nível do mar. Em termos paleoambientais, a seqüêencia deposicional engloba as fácies naturalmente associadas de um sistema ou trato de sistemas deposicionais durante o intervalo de tempo por ela referida.

As seqüências deposicionais podem apresentar-se em diferentes escalas, dependendo da duração e da amplitude da variação relativa do nível do mar. Um ciclo completo transgressivo-regressivo, que Sloss (1963) definiu como seqüência sedimentar, corresponde a uma seqüência deposicional de segunda ordem. Envolve um intervalo de tempo de ordem de 10 a $100 \mathrm{Ma}$, equivalendo-se a períodos da escala geocronológica. Da mesma forma, os sintemas de Ramsbotton (1979) e a facies"cycle wedge de White (1980) equivalem-se às seqüências deposicionais desta ordem de grandeza, o que as torna no instrumento adequado para a Análise de Bacias. Seqüências deposicionais de primeira ordem correspondem a megaciclos de duração superior a $100 \mathrm{Ma}$, equivalendo-se, portanto, a eras da escala geocronológica.

As seqüências deposicionais de terceira ordem ou mesotemas materializam os episódios transgressivos ou regressivos ocorridos em intervalos de tempos da ordem e 1 a $10 \mathrm{Ma}$. Della Favera (1984) cita as cunhas de onlap das bacias marginais brasileiras como exemplos desta ordem de grandeza. As interpretaçōes paleoambientais se valem dessas seqüências, posto que em cada episodio transgressivo ou regressivo a bacia é dominada por uma paleogeografia específica. Constituem, portanto, a unidade natural de interpretação paleoambiental.

Embora questionável em seu conteúdo cronoestratigráfico, admite-se ainda, uma quarta ordem de seqüências deposicionais. Os ciclotemas de Wanless \& Weller (1932) e Ramsbotton (1979) correspondem a seqüências deposicionais desta ordem de grandeza, equivalendo-se a episódios rítmicos de uma mesma província de sedimentação; e envolvem um intervalo de tempo inferior a $1 \mathrm{Ma}$. Goodwin \& Anderson (1980) intro-" duzem o conceito dòs punctuated aggradational cycles (PAC) 
como modelo dessas seqüências. Os sistemas deposicionais, por definição, englobam todos os depósitos rítmicos numa mesma unidade paleogeomórfica.

Della Fávera (1984) acrescenta ainda uma quinta ordem de grandeza citando as tempestades, inundaçöes e terremotos como exemplos:- Entretanto, as seqüências resultantes desses eventos não incorporam a conotação cronoestratigráfica ine. rente ao conceito de seqüência deposicional. Trata-se, na realidade, de processos sedimentares aleatórios responsáveis pelo desenvolvimento de determinadas fácies sedimentares. Como tal, devem ser tratadas em Análise de Fácies e nảo em Análise Seqüêncial.

As sequiências deposicionais são reconhecidas pelo padrão de empilhamento que, em sísmoestratigrafia, é traduzido pelo caráter marcante dos refletores e suas relações geométricas. $\mathrm{Em}$ análise de perfis geofísicos de poços, as seqüências podem ser delímitadas por variações notáveis das propriedades elétricas, radioativas ou acústicas dos sedimentos. Os jazigos fossilíferos com abundante e variada associação faunística, desenvolvidos em unidades destrutivas ou de sedimentação passiva, constituem o melhor critério de campo no reconhecimento dos limites de sequêencias.

Em termos finais, a utilização da Análise Seqüencial em interpretações paleogeográficas objetiva a identificação das seqüências deposicionais de terceira ordem. Essas são unidades naturais que reúnem integralmente os sedimentos depositados numa paisagem geográfica persistente durante um episódio de sedimentaçăo. Os PACs ou seqüências de quarta ordem, que materializam os episodios rítmicos da mesma paisagem geografica, podem igualmente ser utilizadas como unidades de interpretação paleoambiental em áreas restritas de uma bacia. Esta abordagem se justifica na exploração de depósitos estratiformes, onde a maior densidade e a qualidade dos dados geológicos disponíveis permitem um maior detalhamento.

\section{A SEQÜENCIA PERMOCARBONÍFERA DA BACIA}

\section{DO PARANÁ Na Bacia do Paraná, os sedimentos de} idade permocarbonífera compōem uma seqüência deposicional constituída, predominantemente, por clásticos terrígenos. Soares et al. (1978), reconhecendo-a como uma seqüência sedimentar no sentido de Sloss (1963), correlacionaram-na com equivalentes das bacias do Amazonas, Maranhão, Canadá e Plataforma Russa, demonstrando que seu desenvolvimento é decorrência de um evento geológico de âmbito global, relacionado com mudanças eustáticas do nível do mar. De fato, a seqüência permocarbonífera é delimitada por discordâncias regionais (Fig. 2) e constituída por um conjunto de estratos concordantes que materializa um ciclo transgressivo-regressivo completo. Assim, os sedimentos Itararé, Aquidauana, Rio Bonito, Palermo, Tatuí, Irati, Serra Alta, Corumbataí, Teresina e Rio do Rasto compóem uma seqüência deposicional de segunda ordem.

$\mathrm{Na}$ evolução deste ciclo essencialmente terrígeno, os sedimentos carboníferos Irati determinam uma descontinuidade deposicional indicativa de um interregno entre episódios de sedimentação terrígena. Essa inferência tem apoio na ubiqüidade e sincronismo desses sedimentos em toda a Bacia do $\mathrm{Pa}$ raná, separando a Série Rio Tietê, sotoposta, da Série Serra do Espigão; sobreposta (Gama Jr. et al. 1982). Seu caráter cronoestratigráfico, bem como de suas equivalentes formações Whitehill, do Grupo Ecca da África do Sul, e Mangrullo, do Uruguai (Oelofsen \& Aráujo 1983), e decorrente da baixa taxa de sedimentação durante um intervalo de tempo bastante longo.

Os sedimentos da Série Serra do Espigão, objeto do presente trabalho, constituem um conjunto de estratos concordantes delimitados no topo por uma discordância e na base por uma descontinuidade deposicional. Caracteriza-se, portanto, uma seqüência deposicional de terceira ordem, compondo em

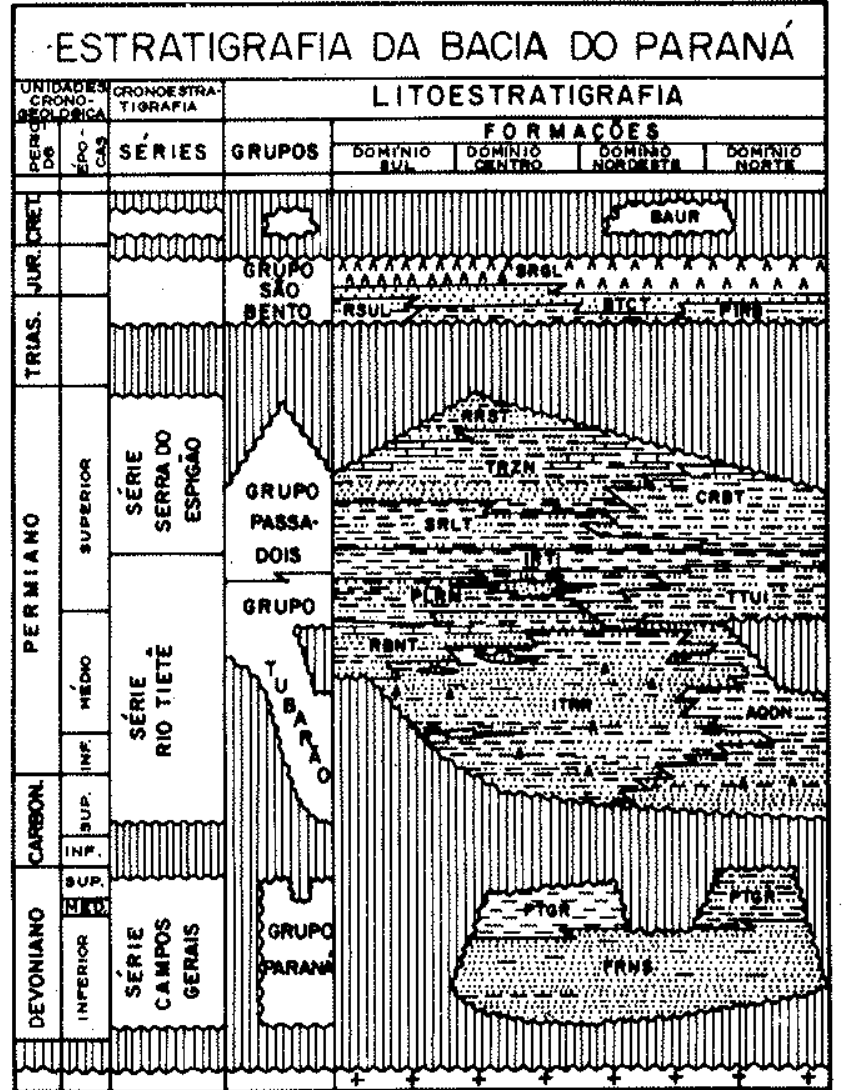

Figura 2 - Estratigrafia da Bacia do Paraná (Gama Jr. et al. 1982)

decorrência uma unidade temporal de interpretação paleogeográfica. Em outras palavras, a Série Serra do Espigão (Grupo Passa Dois, exclusive Formação Irati) identifica um episódio de sedimentação de natureza regressiva, cuja seqüência deposicional apresenta uma sucessão vertical de fácies que corresponde à distribuição horizontal dos ambientes penecontemporâneos. Esta inferência é conseqüência da aplicação da Lei de Correlação de Fácies de Walther (1904), tão negligenciada nos livros-textos clássicos de Estratigrafia (Middleton 1973), mas renascida nos modernos conceitos de sistemas deposicionais e seqüências deposicionais. A conclusão pertinente que se extrai desse enfoque é a Série Serra do Espigão materializar um episódio único de sedimentação: assoreamento de um corpo aquoso, herdado do interregno deposicional Irati. Os processos sedimentares associados a este assoreamento deram origem à associação de fácies de que é composta. Evidentemente, $o$ arranjo tridimensional das fácies componentes e seu empilhamento vertical na faixa de afloramentos são conseqüência da dinâmica tempo-espacial desse assoreamento. Como corolário desta conclusão, as interpretaçōes paleoambientais realizadas em segmentos isolados desta seqüência - por exemplo, as formações - revelam apenas uma parte da paleogeografia geral. Assim, os sedimentos Serra Alta materializam o ambiente subaquoso terminal; os sedimentos Teresina, Serrinha e Corumbataí, os ambientes costeiros progradantes; e os sedimentos Morro Pelado, o ambiente de suprimento terrígeno. Nenhum desses ambientes, quaisquer que sejam suas interpretaçōes paleoambientais, deixaria um registro sedimentar se não coexistissem associados no tempo e no espaço.

A não compreensão desses aspectos metodológicos é a principal razão do desencontro nas interpretações paleoambientais dos sedimentos do Grupo Passa Dois. Mesmo em trabalhos recentes, como o de Petri \& Coimbra (1982), os sedimentos da Formação Teresina são tratados isoladamente. A 
visão parcial da paleogeografia resultou na interpretação de um ambiente inédito em Geomorfologia - laguna terrígena isolada do mar e do suprimento terrígeno. Mais arrojada ainda É a variante dessa interpretação, sugerida por Mendes (1984) - conjunto de lagunas, nas quais a sedimentação resultante seria certamente autigênica pela total impossibilidade de aporte terrígeno.

ANÁLISE DE FÁCIES De uma escala continental para a escala de afloramentos, a Análise de Fácies - domínio da Sedimentologia - constitui a segunda etapa de pesquisas em interpretaçāo paleoambiental. Graças às diagnósticas e conclusivas características das fácies da seqüência deposicional Serra do Espigão, sua interpretação não apresenta grandes conflitos entre os pesquisadores. É geralmente aceita decantação de partículas em águas calmas, abaixo do nível de base das ondas, para a fácies de lamitos Serra Alta (Northfleet et al. 1985 Schneider et al. 1974, Gama Jr. 1979a, Mello e Sousa. 1965). Para as fácies de lamitos Teresina e lamitos Corumbataí, os mesmos autores apontam a presença de correntes de maré como o processo sedimentar mais efetivo e, subordinadamente, decantação de argilas. Petri \& Coimbra (1982) acrescentam as tempestades neste contexto hidrodinâmico. Os processos sedimentares envolvidos na sedimentação da fácies Serrinha são inferidos como costeiros (Schneider et al. op. cit.), sendo resultantes da ação de correntes de maré e posterior lavagem por ondas e correntes litorâneas (Gama Jr. et al. op. cit.). Da mesma forma, correntes de maré são inferidas para a fácies Corumbatá (Gama Jr. op. cit., Mello e Sousa $o p$. cit.). As divergências iniciam-se na extrapolação desses processos sedimentares para os ambientes de sedimentação.

No trabalho já citado, Petri \& Coimbra (1982) analisam as estruturas sedimentares observadas em duas pedreiras: uma da Formação Irati, situada no município de Cesário Lange (SP), e outra da Formação Estrada Nova, no município de Taguaí (SP), como contribuição à reconstituição paleogeográfica do Permiano da Bacia do Paraná. Os dados levantados por esses pesquisadores se ajustam perfeitamente ao modelo de sedimentação proposto por Gama Jr. (1979a) para o Grupo Passa Dois, exclusive Formação Irati. Entretanto, pela adoção de um enfoque metodológico inadequado, seus autores são levados a uma interpretação paleogeográfica discordante. As estruturas sedimentares, assim como outros atributos faciológicos, não são conclusivas quanto ao paleoambiente; representam, sim, as melhores indicaçöes sobre os processos sedimentares forma dores das fácies.

Um dos mais importantes avanços conceituais relacionados no início deste trabalho foi a compreensăo de que as fácies resultam da atuação de processos sedimentares físicos, quími$\cos$ e/ou biológicos, desempenhando os ambientes a função passiva de repositórios dos produtos sedimentares (Fischer \& Brown 1972). O aspecto relevante deste enfoque é que, da mesma forma que um ambiente pode ser dominado por diferentes processos sedimentares, um mesmo processo sedimentar pode-se fazer presente em diferentes ambientes, de tal sorte que a simples interpretação das fácies nảo leva, necessariamente, à interpretação do ambiente.

As estruturas sedimentares primárias, descritas na pedreira de Taguaí (SP), permitem inferir à decantação de argilas, correntes de mare e tempestades como os processos sedimentares dominantes das fácies Teresina. Evidentemente, esses processos não são diagnósticos de lagunas e podem ocorrer em diversos ambientes litorâneos, até em deltas destrutivos dominados por maré. Quanto às estruturas sedimentares pósdeposicionais (gretas de contração, teepees etc.), estas são decorrentes da natureza rítmica da sedimentação deltaica, particularmente em litorais dominados por marés. Em sistemas deltaicos, cada episódio rítmico de sedimentação se inicia com a implantação de um distributário e se encerra com seu abandono. Nos deltas construtivos, os lobos deltaicos abandonados afundam rapidamente nas espessas e ainda inconsolidadas argilas prodeltaicas, propiciando o desenvolvimento dá lutocinese referida por Mendes (1984). Este fenômeno já não ocorre em deltas dominados por marés como o postulado para esta seqüência, pois o menor desenvolvimento prodeltaico impede seu rápido afundamento expondo seus sedimentos à dissecação subaérea e, conseqüentemente, criando estruturas sedimentares pós-deposicionais como as referidas acima. Assim, a presença dessas estruturas pós-deposicionais é perfeitamente consistente e natural em seqüências deltaicas.

Focalizando o trabalho de Petri \& Coimbra (1982) apenas como Análise de Fácies e, como tal, parte necessária mas não suficiente para a reconstrução paleogeográfica, a identificação de tempestades não invalida, igualmente, o modelo apresentado por Gama Jr. (1979a). As tempestades, evidentemente, podem atuar como agente de dispersão de clásticos em qualquer ambiente litorâneo. Sua importância é destacada, entretanto, no ambiente de plataforma transgressiva, semelhante às do Presente. Nessas circunstâncias hidrodinâmicas, as tempestades representam, ao lado do fluxo inercial dos rios no desenvolvimento de deltas e dos agentes glaciais nas regióes árticas, os únicos processos sedimentares capazes de subtrair terrígenos da costa e dispersá-los em águas rasas. Os dados levantados por Emery (1968) confirmam este fato: 70\% da plataforma continental moderna - são recobertas por relíquias; $10 \%$ por sedimentos deltaicos; $5 \%$, por sedimentos glaciais; $10 \%$, por sedimentos autigênicos e biogênicos; e $5 \%$, por sedimentos diversos. Em síntese, cerca de $80 \%$ da plataforma continental atual não são palco de sedimentação terrígena, constituindo os deltas, por meio da progradação costa afora, a excecão mais efetiva. Assim, a interpretação da fácies de lamitos Teresina como prodelta seria perfeitamente compatível com a hidrodinâmica postulada por Petri \& Coimbra (op. cit.).

Entretanto, discorda-se igualmente desta inferência hidrodinâmica. A sedimentação em águas. rasas remonta a uma controvérsia anterior ao próprio reconhecimento das tempestades como processo sedimentar. Até a metade do século, os livros-textos, de modo geral, admitiam que a sedimentação terrígena neste ambiente fisiográfico era uniforme, variando de grossos para finos com o afastamento da costa e aumento de profundidade. Os mecanismos de suprimento e dispersão de terrígenos em águas rasas eram negligenciados pelos geólogos da época, que, simplesmente, admitiam sua presença no ambiente por analogia com a sedimentação autigênica (Shepard 1932). O levantamento realizado por Emery (1968) chamou a atenção para o fato de, no Presente, o transporte de clásticos na plataforma continental se fazer do mar para a terra (Curray 1969). As exceções ficam por conta das correntes de turbidez e as tempestades (Walker 1980). Swiff (1969), entretanto, já esclarecia que tais condiçóes hidrodinấmicas se impōem somente em margens continentais que, em episódios transgressivos semelhantes aos do Presente, apresentam seu perfil longitudinal fora de equilibrio com seus processos sedimentares. Em episódios regressivos ou em áreas onde o perfil de equilibrio da margem continental tenha sido reconstituído, a dispersâo do terrígenos é normal. Nessas condiçōes, as tempestades representam apenas um processo adicional de natureza eventual e secundário. $O$ inquestionável empilhamento progradacional da sequêencia Serra do Espigão demonstra o caráter regressivo desta sedimentação, não se justificando em decorrência a suposta hidrodinâmica de mares transgressivos. Ademais, estranha-se a argumentação hidrodinâmica de Petri \& Coimbra (1982), típica de mares abertos, quando concluem por um ambiente lagunar fechado. Este ambiente, por sua vez, é hidrodinamicamente incompatível com correntes de mare, cuja efetividade como processo sedimentar implica necessariamente comunicação oceânica, como ocorre com os golfos, estuários e baías (Ricci-Luchi 1980). Em mares fechados, as marés são fracas e inócuas na dispersão e deposiçäo de terrígenos, e em mares totalmente abertos para o ocea- 
no a ação das correntes de maré E obliterada pelas ondas e correntes litorâneas.

A conclusão importante a se extrair dessas consideraçöes é que, independente dos aspectos subjetivos da interpretação, a Análise de Fácies realizada isoladamente não é o melhor enfoque para alcançar uma interpretação paleogeográfica. Como recomenda Miall (1984), ela deve ser precedida da identificação das seqüências deposicionais - que permitirá o reconhecimento das fácies temporalmente associadas num episódio de sedimentação - e completada com o mapeamento dos sistemas deposicionais, que delineará a paleogeografia no intervalo de tempo referido pela seqüencia deposicional.

SISTEMAS DEPOSICIONAIS AO analisar a interpretação de Schneider et al. (1974) para os seđimentos Teresina e a de Gama Jr. (1979a) para a associação de fácies do Grupo Passa Dois, Mendes (1984) infere planíceis de maré de $1.500 \mathrm{~km}$ e deltas de $500 \mathrm{~km}$ de extensão. Estas são as dimensões do registro sedimentar preservado ou dos sistemas deposicionais inferidos, não guardando nenhuma relação com a forma e as dimensões originais de seus ambientes deposicionais. Poder-se-ia contra-argumentar que bastaria um ambiente costeiro com apenas $10 \mathrm{~km}$ de extensão, progradando à razăo média de $20 \mathrm{~m} /$ ano, para recobrir num epiśdio de $5 \mathrm{Ma}$ uma área de 1 milhão $\mathrm{km}^{2}$ ! É obvio que tanto este raciocínio quanto a inferência acima são sofismas geológicos, mas que se prestam adequadamente para contrapor a visão estática đa estratigrafia de formações tabulares - na qual os litossomas e ambientes guardam entre si as mesmas relações geomótricas (bolo e assadeira) - com a visão moderna, onde os ambientes costeiros são extremamente dinâmicos no tempo e no espaço (enceradeira no salão).

A materialização do ambiente no espaço de bacia e sua evolução no tempo referido pelo episódio de sedimentação são conferidas pelo conceito de sistema deposicional. Sua aplicação em interpretação paleoambiental de uma sequêencia deposicional de terceira ordem envolve, basicamente, a resposta para a seguinte questão: qual a província fisiográfica ou geomorfologica em que comparecem num inter-relacionamento genético os processos sedimentares inferidos pela Análise de Fácies desta seqüência deposicional? A par da analogia com o Presente, implícito no conceito de sistema deposicional, o método prevề a integração de evidências extraídas das características internas das fácies (processos sedimentares envolvidos, significado ambiental dos fosseis e dos dados geoquímicos, significado evolutivo dos contatos etc.) com evidências relacionadas à distribuiição, geometria e trato de fácies e/ou sistemas deposicionais e suas relações tridimensionais. Mapas de isópacas, de isólitas de arenito e seçōes estratigráficas longitudinais e transversais ao mergulho deposicional constituem as técnicas comumente utilizadas nesse mister. É importante ressaltar que a utilização de conceito de sistemas deposicionais implica, necessariamente, no reconhecimento de unidades paleogeomorficas cartografadas em mapas paleogeográficos do episódio de sedimentação envolvìdo. São esses mapas que materializam a reconstituição paleogeográfica, pois situam geograficamente as províncias de sedimentação inferidas.

O conceito de sistema deposicional vem sendo impropriamente divulgado no Brasil como simples análise de fácies. Esta abordagem representa uma grave distorção metodológi$\mathrm{ca}$, pois retira desse conceito seu aspecto mais relevante, qual seja, uma unidade paleogeomórfica definida pela associação de fácies formadas numa mesma província geográfica. É esta concepção que the empresta a importância que detém na moderna Estratigrafia - uma unidade genética de mapeamento. Este mapeamento é aplicável tanto na bacia como um todo, pelas técnicas estratigráficas usuais, como na cartografia geológica da faixa de afloramentos da seqüência deposicional em questão. $O$ primeiro caso se justifica no reconhecimento inicial dos sistemas deposicionais, ou seja, na interpretação paleoambiental, enquanto o mapeamento em superfície cristaliza sua aplicabilidade na prospecçăo de depósitos estratiformes, como carvão, urânio e sulfetos metálicos.

Nesses termos, o conceito de sistema deposicional representa uma ponte entre a Sedimentologia e a Estratigrafia. Vale dizer, o elo que permite situar os processos inferidos pela Análise de Fácies no ambiente deposicional e sua evolução no episódio de sedimentação referido pela seqüência deposicional. A não compreensão dessa dimensão tempo-espacial levou Mello e Sousa (1985) a projetar os processos sedimentares, interpretados pela Análise de Fácies realizada em sedimentos do Grupo Passa Dois no Estado de São Paulo, para uma paleogeografia estática no intervalo de tempo envolvido. Inferiu, conseqüentemente, um empilhamento por acréscimo vertical à semelhança de "bolo em camadas". Tivesse essa autora atravessado a ponte entre a Sedimentologia e a Estratigrafia, complementando sua criteriosa Análise de Fácies com a identificação e mapeamento de sistemas deposicionais, teria alcançado uma reconstituição paleogeográfica idêntica à postulada por Gama Jr. (1979a) para esta área da bacia

$\mathrm{O}$ único mapeamento de sistemas deposicionais realizado no Grupo Passa Dois da Bacia do Paraná é devido a Gama Jr. (1979a, 1979b). A sequência deposicional Serra do Espigão (Grupo Passa Dois, exclusive Formação Irati) 6 interpretada como um epis6dio de assoreamento de um golfo preexistente. Três sistemas deposicionais terrígenos concorrem penecontemporaneamente neste episódio: sistema de plataforma epinerítica, cujo mapa de isopacas demonstra que o golfo original se deveria estender além da atual borda leste; o sistema deltaico Serra do Espigão, destrutivo dominado por marés, cujo arcabouço arenoso é mapeado pelas iślitas de arenito (Figs. $3 \mathrm{e}$ 4) - estes mapas demonstram a área-fonte a noroeste com progradação para sudeste; e, finalmente, o sistema de planície de maré Corumbataí, significantemente desenvolvido no extremo nordeste de postulado golfo, progradando de São Paulo para o Paraná.

O sistema deltaico Serra do Espigão, por ser o sistema dominante neste episódio, é o elemento crítico dessa interpretação. Os deltas representam a província de sedimentação mais efetiva dentre os ambientes deposicionais. Em condições marinhas, onde a sedimentação terrígena é suprida por rios, este ambiente se apresenta como primeira alternativa deposicional. Este aspecto, aliado ao fato de os deltas se desenvolverem em áreas subsidentes propícias a sua preservação, torna o sistema deltaico um dos mais abundantes de registro geológico. Entretanto, seu reconhecimento encontra algumas dificuldades, relacionadas, principalmente, com a geometria do sistema e seu conteúdo fóssil.

O ambiente deltaico, como se visualiza no Recente, apresenta uma configuração e dimensões de um epiśdio de sedimentação de quarta ordem de grandeza - o atual com apenas poucas centenas de anos. $O$ sistema deposicional representa a somatória dos depósitos deltaicos de todos os episodios rítmicos desenvolvidos durante o intervalo de tempo de existência dessa fisiografia. Este intervalo de tempo constitui um episódio de terceira ordem referido pela sequiência deposicional. Em cada episodio rítmico ou ciclo deltaico, os deltas progradam mar adentro, produzindo um depósito tridimensional de forma lobada. As taxas de programação são extremamente elevadas: $91 \mathrm{~m} /$ ano para o delta do Mississípi a $268 \mathrm{~m} /$ ano para o Yellow Plain (Smith 1966). A repetição de ciclos provoca a imbricação dos depósitos pelíticos sub-aquosos, desfigurando sua forma original e conferindo-lhe, paulatinamente, uma geometria tabular. $O$ mesmo ocorre com a parte subaerea de natureza fluvial; somente a frente deltaica preserva a individualidade de cada ciclo.

Assim sendo, as dimensões finais dos sistemas deltaicos não guardam nenhuma similaridade com as dimensões originais de seu ambiente original. Dependerá, entre outros fatores, de: a. dimensões da bacia marinha; b. relação taxa đe su- 


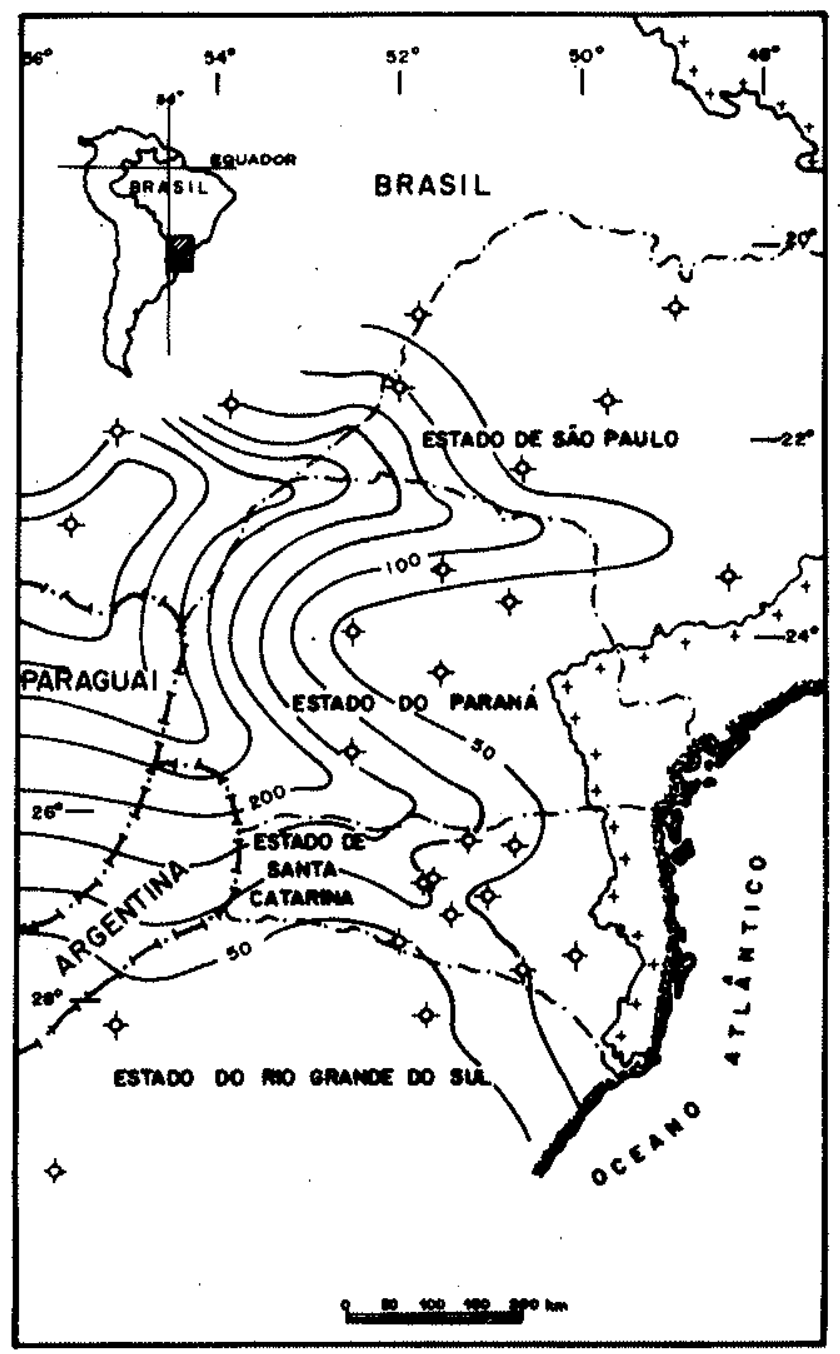

Figura 3 - Isólitas de arenito do sistema deltaico Serra do Es pigão: seção subaquosa (Gama Jr. 1979a)

primènto $x$ energia marinha, que se refletirá na taxa de progradação de cada ciclo deltaico; e c. taxa de sedimentação $x$ taxa de subsidência, que determinará o padrão de empilhamento e, conseqüentemente, de arranjo tridimensional de suas fácies. Considerando a alta taxa de suprimento terrígeno nos ambientes deltaicos relativamente à taxa de subsidência de bacia interiores, é lícita a imagem que os sistemas deltaicos, assim como os liquidos, possuem a geometria da bacia que os contém. Como ilustração desta imagem, o sistema deltaico moderno do Mississípi, abrangendo cinco ritmos de quarta ordem em apenas 6.000 anos, já recobriu com uma espessura média de 600 pés de sedimentos uma área superior a 20.000 milhas quadradas (Frazier 1967), ou seja, uma área equivalente à extensão sedimentar do Estado de Santa Catarina.

Quanto ao conteúdo fóssil, os sistemas deltaicos são caracterizados pela mistura de fósseis continentais e marinhos que, antes de representarem motivo de controvérsias, constituem uma evidência diagnóstica. As planícies e frentes deltaicas configuram um nicho ecológico particularmente adequado para o desenvolvimento de ricas faunas e intensa flora. Barberena et al. (1980) atribuem a esta condição a presença dos tetrápodos na Formação Rio do Rasto. Já o ambiente prodeltaico não apresenta condiçóes ecológicas ideais para o desenvolvimento de intensa fauna marinha, em razão da alteração dos parâmetros ecológicos (salinidade, temperatura, turbidez

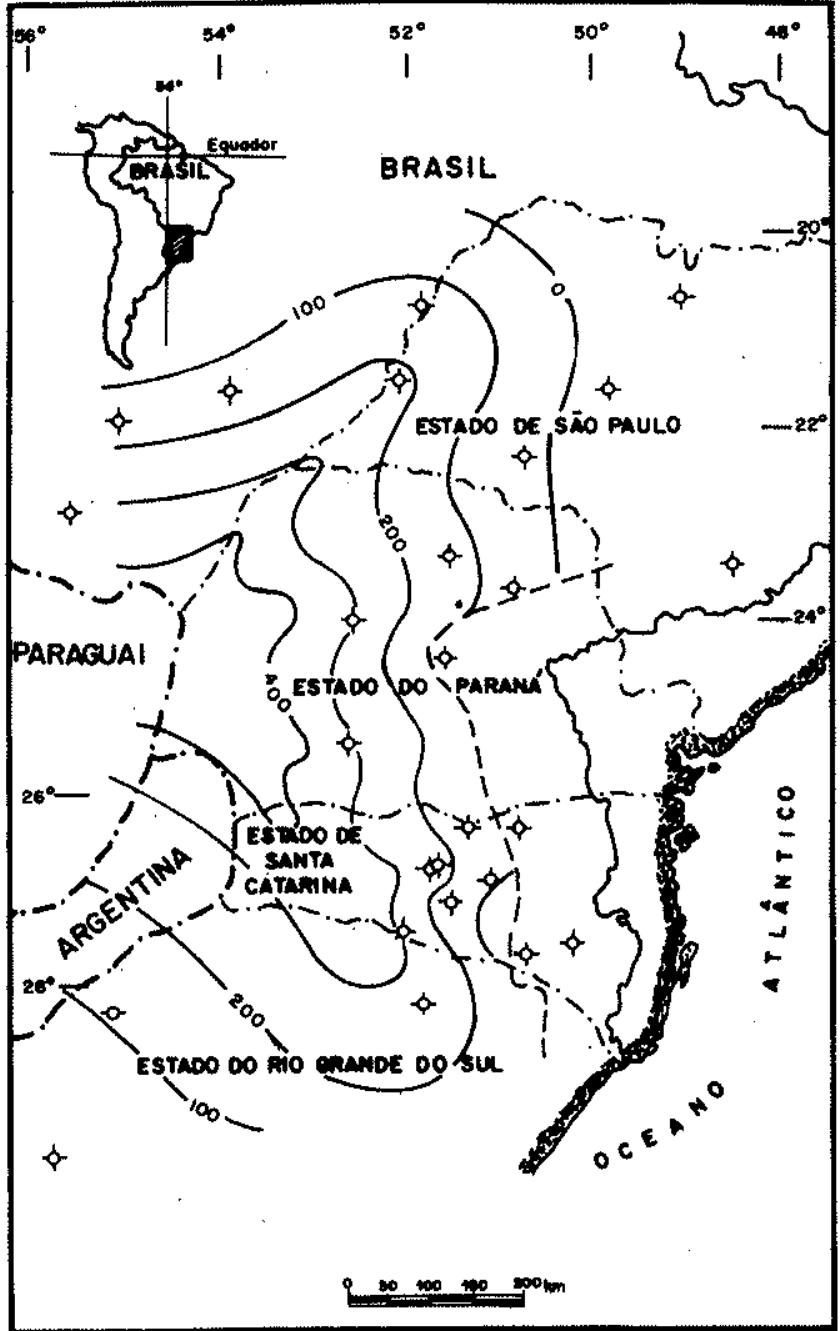

Figura 4 - Isólitas de arenito do sistema deltaico Serra do Espigão: seção subaérea. (Gama Jr. 1979a)

etc.) verificada nas proximidades das desembocaduras fluviais. Apesar desse fator limitante, fósseis marinhos têm sido descritos nas fácies subaquosas desta seqüência (in Mendes 1984). Como decorrência, os sistemas deltaicos marinhos representam, depois dos lagos, a província fisiográfica mais propícia à preservação de fósseis continentais. Além dos parâmetros ecológicos já referidos, três outros fatores concorrem para essa preferencial: a. a descarga fluvial em ambientes salinos, mesmo diluídos, provoca uma grande mortandade nos seres aquáticos de hábito dulcícola. Assim, para esses organismos, o prodelta representa o ambiente de sua morte e não $o$ de sua vida; b. o fluxo hipopicnal (Bates 1953) gerado pela descarga fluvial ao adentrar o reservatorio marinho é menos abrasivo que as correntes fluviais. Como conseqüencia, os restos orgânicos, animais e vegetais, que tenham superado a ação destruidora das correntes fluviais, encontram melhores condiçōes de preservação no ambiente marinho. Dada a riqueza faunística e florística nas planíceis deltaicas, a probabilidade de incorporação de restos orgânicos próximo à foz é grande, resultando sua preservaçâo sem grandes evidências de rêtrabalhamento; e c. as condiçoes redutoras reinantes nos ambientes prodeltaicos săo mais adequadas à fossilização do que a maioria dos ambientes continentais.

A implicação relevante dessas consideraçōes é que a presença de fósseis continentais na seqüência marinha Serra do 
Espigão representa uma evidência positiva de sua interpretação como sistema deltaico. $\mathrm{A}$ indústria do petróleo, desde a introdução da Geoquímica Orgânica, reconhece que as seqüências deltaicas, mesmo marinhas, não são grandes geradoras de petróleo; pelo contrário, sua vocação natural é de geração de hidrocarbonetos gasosos, dada a predominância de matéria orgânica vegetal de origem continental. No aspecto metodológico, é importante ressaltar que a interpretação paleontológica de sedimentos terrígenos, particularmente marinhos, deve sempre considerar a possibilidade de que os fósseis sejam alóctonos, posto que os fragmentos inorgânicos constituintes da rocha fossilífera são, obviamente, derivados do continente.

CONCLUSÕES E CONSIDERAÇÕES FINAIS A seqüência pemocarbonífera da Bacia do Paraná é aqui interpretada como uma facies-cycle wedge (White 1980): um ciclo transgressivo-regressivo completo com os sedimentos marinhos e continentais apresentando uma distribuição tempo-espacial em forma de cunhas superpostas e penecontemporâneas. (Fig. 5).

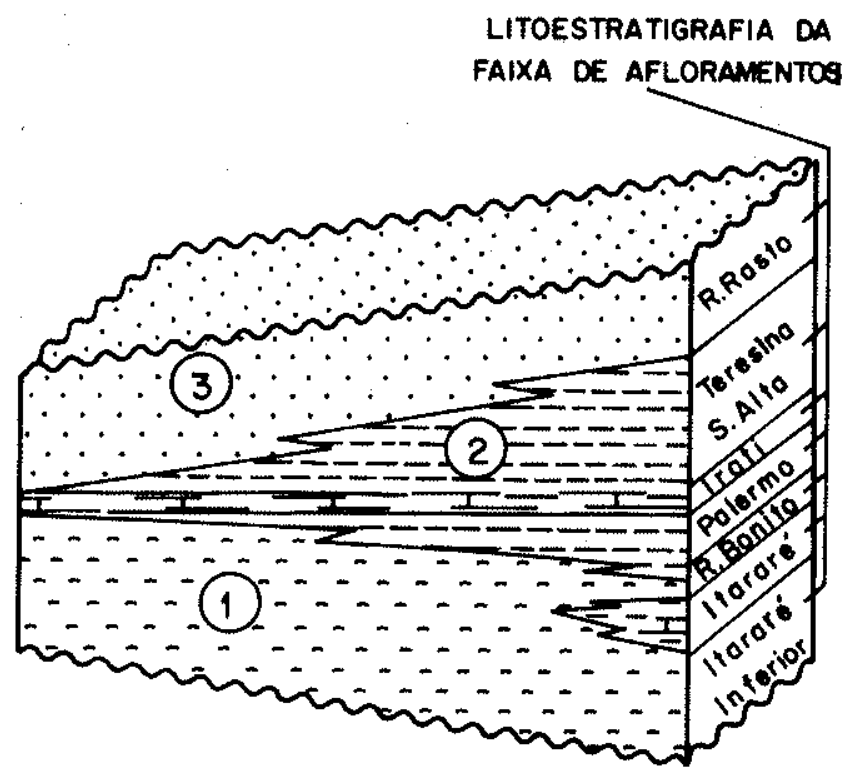

\section{(1) Continental de base \\ (2) Marinho \\ (3) Continental de topo}

Figura 5 - Facies-cycle wedge do permocarbonifero da Bacia do Paraná

A fase transgressiva é registrada pela Série Rio Tietê, que, englobando duas ou mais seqüencias deposicionais de terceira ordem, reúne sedimentos formados numa paisagem glacial em contínua deterioração. Os ambientes evoluem, no espaço e no tempo, de continentais para costeiros e destes para marinhos rasos em resposta à contínua transgressão; esta, por sua vez, 6 decorrente do levantamento relativo do nível do mar, de âmbito mundial, que na Bacia do Paraná sofreu forte influência da deglaciação gondwânica: A evolução dessa paisagem, acompanhando a melhoria climática, vai gradativamente reduzindo a importância dos processos sedimentares de influência glacial, em favor de processos fluvialmente controlados. O clímax é atingido quando toda a extensão da área subsidente é dominada por um ambiente marinho raso de características epicontinentais; o novo nível de base, afogando a drenagem contributária, impede o aporte de terrígenos à bacia. Encerrase assim a fase transgressiva de sedimentação terrígena. A bacia passa então a ser dominada por sedimentação carbonática e/ou passiva, traduzida pelas fácies Irati, que Oelofsen \& Araújo (1983) interpretam como uma baía posicionada entre a América do Sul e a África.

$O$ reajuste dos agentes de trasporte, suprimento e dispersāo dos terrígenos ao novo nível de base marca o início do episódio regressivo, traduzido pela seqüência deposicional Serra do Espigão. Originalmente, o ambiente marinho se apresenta sob a forma de golfo, aberto para sudeste, cujos limites interiores atingiam a regiăo de Mato Grosso e Goiás, estendendo-se para leste além dos atuais limites da bacia. Os ambientes evoluem, desta vez, de marinhos para costeiros e destes para continentais como resposta ao assoreamento por três sistemas deposicionais: a. sistema de plataforma epinerítica Serra Alta, cujo mapa de isópacas e de tendência de espessura (Gama Jr. 1979a) materializa o ambiente original de sedimentação desta seqüência deposicional: um golfo aberto para sudeste; b. sistema deltaico Serra do Espigão, do tipo destrutivo dominado por marés, é o principal agente de suprimento e dispersão de terrígenos e o principal responsável pelo assoreamento do golfo original. Derivado das terras altas do cinturão ParaguaiAraguaia, conforme se depreende dos mapas de isólitas de arenito (Gama Jr. op. cit.), esse sistema prograda de noroeste para sudeste em inúmeras pulsações rítmicas; e c. sistema de planície de maré Corumbataí, que completa a paisagem geográfica como uma província marginal de fundo de golfo nas regiōes de São Paulo e Goiás. Admite-se como provável que outro sistema marginal se tenha desenvolvido na região do Rio Grande do Sul, contemporaneamente aos demais sistemas costeiros.

A interpretação acima encontra apoio nos dados geológicos obtidos por diferentes métodos de análise paleoambiental e relacionados a seguir:

- Análise seqüêncial - A seqüência deposicional de terceira ordem Serra do Espigão caracteriza-se por empilhamento progradacional, típico de ambientes litorâneos com alto suprimento terrígeno. Esta característica é marcante em sistemas deltaicos.

- Análise de fácies - Os processos sedimentares inferidos para as diferentes fácies descritas nesta seqüência (Northfleet et al. 1969, Schneider et al. 1974, Gama Jr. 1979a, 1979b, Petri \& Coimbra 1982, Mello e Sousa 1985) são compatíveis com o modelo de sedimentação postulado.

- Trato de fácies - A distribuição, geometria e arranjo tridimensional das fácies componentes desta seqüência, conforme se constata em mapas e seçōes estratigráficas (Gama Jr. 1979a), ajustam-se corretamente à concepção ideal e teórica da interação dos postulados sistemas deposicionais.

- Dados geoquímicos - A paleossalinidade registrada por dados geoquímicos (Rodrigues \& Quadros 1976) evidencia uma diluição crescente para oeste-noroeste, de onde se admite 0 suprimento fluvial e conseqüente progradaçăo deltaica. No extremo leste da bacia registram-se os valores mais altos de salinidade, indicando assim a direção do mar aberto.

- Conteúdo fóssil - A abundância de fósseis continentais e a escassez de fósseis marinhos preservados em sedimentos marinhos são uma forte indicação da proximidade de desembocamento de rios e, consequientemente, da presença de sedimentação deltaica.

- Paleocorrentes - As direções das paleocorrentes medidas por Bigarella \& Salamuni (1967) apontam uma dispersão de terrígenos de oeste-noroeste para leste-sudeste, acompanhando a inferida direção de progradação deltaica e sua área-fonte. Apenas no Rio Grande do Sul, onde se admite o desenvolvi- 
mento de um outro sistema deposicional, as paleocorrentes apresentam direções divergentes.

- Geoquímica orgânica - A predominância de macerais de origem vegetal relativamente aos de origem marinha, associados a sedimentos marinhos desta seqüência, é indicativa de sistemas deltaicos.

- Inversão de mergulhos - Na faixa de afloramentos da borda leste da Bacia do Paraná, os sedimentos da seqüência deposicional em questão apresentam uma inversão de mergulhos, deposicional e estrutural. O mergulho deposicional, reconhecido pela direção de paleocorrentes e pelo trato de fácies, é de oeste-noroeste para leste-sudeste enquanto o mergulho estrutural é de leste para oeste. Esta inversão é atribuída ao soerguimento do litoral sul-brasileiro por ocasião da ruptura e separação dos continentes sul-americano e africano no Mesozóico. Este soerguimento, ao criar o relevo acidentado da região litorânea, expôs à erosão a extensão leste da então área sedimentar, fazendo retroceder os limites da bacia para a atual posição, onde se mostra basculada para oeste. Assim, esta inversão é indicativa de que o ambiente original de sedimentação desta seqüência se estendia além dos atuais limites, o que se compatibiliza com o postulado golfo aberto para sudeste e assoreado de noroeste.

Como consideração final, acrescenta-se que um dos fatos mais negligenciados na interpretação paleoambiental desta seqüência se refere à natureza terrígena desses sedimentos. Em ambientes marinhos, este aspecto significa, com raras exceções, que o suprimento se fez pela descarga de rios. Considerando as características texturais desses sedimentos, particularmente a predominância de pelitos, esse suprimento teria de ser realizado por rios de elevado número de ordem, com todas as implicações que este conceito geomorfológico traduz: rios de alta capacidade e baixa competência; com baixo declive longitudinal, elevado número de contributários e extensa área de drenagem; rios lentos, volumosos e retilíneos. Assim, qualquer que seja a interpretação do ambiente subaquoso terminal, a reconstituição paleogeográfica desse episódio sedimentar deve contemplar uma planície fluvial de grande extensão geográfica. Essa consideração tem implicação com as interpretações postuladas por outros autores para os sedimentos Teresina. Os ambientes de planície de maré e lagunar jamais ocorrem isolados numa província de sedimentação. Pelo contrário, estão sempre associados, marginalmente, a ambientes deltaicos ou estuarinos. Além da observação do Presente, esta constatação deriva do fato de os referidos ambientes não serem auto-suficientes no suprimento de terrígenos. Dependem sempre da alimentação fluvial e de uma hidrodinâmica litorânea adequada.

Agradecimentos $\mathrm{O}$ autor agradece aos colegas José Alexandre de J. Perinotto e Reinaldo José Bertini pela leitura crítica e sugestões apresentadas.

\section{REFERÊNCIAS BIBLIOGRÁFICAS}

BARBERENA, M.C.; CORREIA, N.R.; AUMONT, A.A. - 1980 Contribuição à estratigrafia e bioestratigrafia do Grupo Passa Dois na Serra do Cadeado (Nordeste do Paraná, Brazil). Rev. Bras. Geoc., 10(4):268-275.

BATES, C.C. - 1953 - Rational theory of delta formation. Am. Assoc. Petrol. Geol. Bull., 37:2119-2162.

BIGARELLA, J.J. \& SALAMUNI, R. - 1967 - Some paleogeographic and paleotectonic features of the Paraná Basin. In: BIGARELLA, J.J.; BECKER, R.D.; PINTO, I.D. eds. Problems in Brazilian Gondwana Geology. Curitiba, Instituto de Geologia, Universidade Federal do Paraná. p. 235-301.

CURRAY, J.C. - 1969 - History of continental shelves. In: A.G.I. ed. The new concepts of continental margin sedimentation. Washington, AGI (Short course lecture notes). p. 6.1-6.18

DELLA FAVERA, J.C. - 1984 - Eventos de sedimentação episódica nas bacias brasileiras. Uma contribuição para atestar o caráter pontuado de registro sedimentar. In: CONGR. BRAS. GEOL., 33, Rio de Janeiro, 1984. Anais... Rio de Janeiro, SBG, v. 3, p. 489-501.

DIETZ, R.S. - 1963 - Wave base, marine profile of equilibrium and wave built terraces: a critical appraisal. Geol. Soc. Am. Bull., 24:971-990

DUNBAR, C.O. \& RODGERS, J. - 1957 - Principles of stratigraphy. New York, John Wiley and Sons. 356 p.

EMERY, K.O. - 1968 - Relict sediments and continental shelves of the world. Amer. Assoc. Petrol. Geol. Bull., 52:445-464.

FISHER, W.L. \& BROWN JR., L.F. - 1972 - Clastic depositional systems: a genetic approach to facies analysis. Austin, Univ. Texas/Bur. Econ. Geology. 211 p.

FISHER, W.L. \& McGOWEN, J.H. - 1967 - Depositional systems in the Wilcox Group of Texas and their relationship to occurrence of oil and gas. Gulf Coast Assoc. Geol. Socs. Trans., 17:105-1 125.

FRAZIER, D.E. - 1967 - Recent deltaic deposits of the Mississipi Delta: their development and chronology. Gulf Coast Assoc. Geol. Socs. Trans., 17:287-315.

GAMA JR., E.G. - 1979a - A sedimentação do Grupo Passa Dois (exclusive Formação Irati): um modelo geomórfico. Rev. Bras. Geoc., 9(2):1-16

GAMA JR., E.G. - 1979b - Sistemas deposicionais do Grupo Passa Dois. In: SIMP. REG. GEOL., 2, São Paulo, 1979. Atas... São Paulo, SBG/NSP, v. 1, p. 195-282.

GAMA JR., E.G.; BANDEIRA JR., A.N.; FRANÇA, A.B. - 1982 Distribuição espacial e temporal das unidades litoestratigráficas paleozóicas na parte central da Bacia do Paraná; Rev. Bras. Geoc., 12(4):578-589.

GOODWIN, P.W. \& ANDERSON, E.J. - 1980 - Punctuated aggradational cycles: a general hypothesis of stratigraphic acumulation In: ANNUAL MEETING, 13, Atlanta, 1980. Abstracts...Atlanta, Geol. Soc. Amer., p. A1-A12.

KRUMBEIN, W.C. \& SLOSS, L.L. - 1953 - Stratigraphy and sedi- mentation. 2 ed. San Francisco, W.H. Freeman. 660 p.

MELLO E SOUSA, S.H. - 1985 - Fácies sedimentares das formações Estrada Nova e Corumbataí no Estado de São Paulo. São Paulo, 142 p. (Dissertação de Mestrado, IGUSP) (inédita).

MENDES, J.C. - 1984 - Sobre os paleoambientes deposicionais do Grupo Passa Dois. Rev. IG., 5(1/2):14-24.

MIALL, A.D. - 1985 - Principles of sedimentary basin analysis. $2 \mathrm{ed}$ New York, Springer-Verlag. $490 \mathrm{p}$.

MIDDLETON, G.V. - 1973 - Johannes Walther's Law of the correlation of facies. Geol. Soc. Am. Bull., 84:979-988.

NORTHFLEET, A.A.; MEDEIROS, R.A.; MUHLMANN, H. - 1969 - Reavaliação dos dados geológicos da Bacia do Paraná. Bol.Tec. da Petrobrás, 12(3):291-346.

OELOFSEN, B. \& ARAÚJO, D.C. - 1983 - Palaeocological implications of the distribution of mesossaurid reptiles in the Permian Irati Sea (Paraná Basin) South America. Rev. Bras. Geoc., 13(1):111.

PETRI, S. \& COIMBRA, A.M. - 1982 - Estruturas sedimentares das formações Irati e Estrada Nova (Permiano) e sua contribuição para elucidação de seus paleoambientes geradores, Brasil, In: CONGR. LATINO-AMERICANO DE GEOLOGIA, 5, Buenos Aires, 1982. Actas... Buenos Aires, Associación Paleontológica Argentina, v. 2, p. 353-371.

RAMSBOTTON, W.H.C. - 1979 - Rates of transgression e regression in the Carboniferours of NW Europe. J. Geol. Soc. London, 136: 147-153.

RICCI-LUCHI, F. - 1980 - Sedimentologia. Bologna, Coop. Lib. Univ. Editrice Bologna. $545 \mathrm{p}$.

RODRIGUES, R. \& QUADROS, L.P. - 1976 - Mineralogia das argilas e teor de boro das formaçôes paleozóicas da Bacia do Paraná. In: CONGR. BRAS. GEOL., 25, Ouro Preto, 1976. Anais... Ouro Preto, SBG. v.2, p. 351-379.

SCHNEIDER, R.L.; MUHLMANN, H.; TOMMASI, F.; MEDEIROS, R.A.; DAEMON, R.F. - 1974 - Revisão estratigráfica da Bacia do Paraná. In: CONGR. BRAS. GEOL., 28, Porto Alegre. Anais.. Porto Alegre, SBG. v.1, p. 41-65.

SHEPARD, F.D. - 1932 - Sediments on the continental shelves. Geol. Soc. Am. Bull., 43:1017-1039.

SLOSS, L.L. - 1963 - Sequences in the cratonic interior of North America. Geol. Soc. Am. Bull., 74:93-113.

SMITH, A.E. - 1965 - Modern deltas: comparison maps. In: SHIR LEY, M.L. ed. Deltas in their geologic framework. Houston, Houston Geological Society. 1-251 p.

SOARES, P.C.; LANDIM, P.M.B.; FULFARO, V.J - 1978 - Tectonic cycles and sedimentary sequences in the Brazilian intracratonic basins. Geol. Soc. Am. Bull., 89:181-191.

SWIFT, D.J.P. - 1969 - Inner shelf sedimentation: processes and products. In: A.G.I. ed. The new concepts of continental margin sedimentation. Washington. AGI (short course lecture notes) p. 4.1-4.46. 
VAIL, P.R.; MITCHUM JR., R.M.; THOMPSON III, S. - 1977 Seismic stratigraphy and global changes of sea level. Part 3: Relative changes of sea level from coastal onlap. In: PAYTON, C.E. ed. Seismic stratigraphy application to hidrocarbon exploration. Tulsa. Am. Assoc. Petrol. Geol. (Memoir 26), 1977. p. 63-82.

WALKER. R.G. $-1980-$ Facies models. 2 ed. Toronto, Geol. Assoc. of Canada. (Geosci. Can., Reprint Series 1). 211 p.

WALTHER, J. - 1894 - Einlentung in die Geologie als Historische Wisenschaft. Jena, Fisher Verlag. 3 v. 1055 p.
WANLESS, H.R. \& WELLER, J.M. - 1932 - Correlation and extent of Pensylvanian cyclothems. Geol. Soc. Am. Bull., 43:1003-1016.

WHITE, D.A. - 1980 - Assessing oil and gas plays in facies"cicle wedges. Am.Assoc.Petrol.Geol.Bull., 64(8):1140-1157.

MANUSCRITO 418

Recebido em 11 de fevereiro de 1987 Revisão aceita em 29 de setembro de 1987

Mas a educaçăo aqui no Brasil p'rá que serve? Porque o que $\epsilon$ incontestável $\epsilon$ que o curso primário năo desanalfabetiza, o secundário não humaniza - e o superior nem faz profissionais, nem faz sábios, nem faz pesquisadores :

Oswald de Andrade \& Patricia Galvão, 1931 (do jornal "O Homem do Povo"). 